\title{
Factors Associated with Non-compliance with Anti-malarial Treatment among Malaria Patients in Puerto Princesa, Palawan
}

\author{
Analigaya R. Agoncillo, Kristine Ayessa Elaine B. Coronacion, Julienne Theresa T. Dagdag, \\ Ma. Stephanie C. Matira, Niña Kashka E. Pamintuan, Charles Sherwin M. Soriano, \\ Maria Sonia S. Salamat, Ofelia P. Saniel and Pilarita T. Rivera \\ College of Public Health, University of the Philippines Manila
}

\begin{abstract}
Objective. Malaria is a life-threatening, mosquito-borne disease that continues to cause numerous deaths worldwide. In the Philippines, malaria remains an important problem, with five provinces having $>1000$ cases of malaria a year. The objective of this cross-sectional analytical study was to determine the association of selected factors with non-compliance to antimalaria treatment among malaria patients in Puerto Princesa, Palawan, specifically: perceived susceptibility to malaria, perceived seriousness and severity of malaria, perceived benefits of medication, perceived barriers to treatment compliance and cues to action.
\end{abstract}

Methods. Using an interviewer-administered structured questionnaire, 320 individuals diagnosed with and treated for malaria from January to October 2010 were interviewed regarding compliance to anti-malarial treatment and the factors related to compliance. Descriptive statistics and multiple logistic regression were used to analyze the data.

Results. The rate of non-compliance to anti-malaria treatment was $17 \%$ (95\% Cl 12.1\%-21.2\%). After multivariate analysis using logistic regression, symptom perception as a cue to action and forgetfulness as a perceived barrier to treatment compliance were found to be significantly associated with non-compliance to treatment. The odds of non-compliance were three times higher for individuals who perceived that an improvement in symptoms implied cure of malaria. An individual who forgot to take at least one dose of medication was 17 times more likely to be non-compliant with treatment compared to someone who did not forget to take a single dose.

Conclusion. Given the factors found to be associated with noncompliance to treatment, more effective ways of ensuring compliance with anti-malaria treatment may be explored e.g., doing directly observed treatment and utilizing treatment

Presented at the Transformative Research, Call for Action, and Advocacy: AIDS, TB \& Malaria National Health Research Forum, Feb. 23, 2012, UPManila National Institutes of Health/Hyatt Regency Hotel and Casino (oral presentation in a simultaneous symposium).

Corresponding author: Maria Sonia S. Salamat, MD, FPCP, FPSMID Department of Parasitology

College of Public Health

University of the Philippines Manila

625 Pedro Gil Street, Ermita, Manila 1000 Philippines

Telephone: +6325235929

Email: mssalamat@up.edu.ph partners that may help address the problem of forgetfulness. The fact that symptom improvement is not equivalent to cure must be stressed when advising patients. Emphasizing compliance to treatment and the consequences of noncompliance when conducting patient education activities may also help boost treatment compliance.

Key Words: Malaria, patient compliance, therapeutics

Introduction

Malaria is a life-threatening disease caused by Plasmodium species and transmitted by Anopheles mosquito vectors. In 2012, malaria caused 627,000 deaths worldwide in 2012. ${ }^{1}$ Currently, there are five Category A provinces in the Philippines. Category A provinces have more than 1,000 malaria cases per year. Predominant species are $P$. falciparum that causes $69 \%$ of cases and $P$. vivax that causes the rest. ${ }^{2}$ Because of the worldwide problem caused by malaria, it is included in one of the millennium development goals, MDG 6, which endeavors to combat HIV/AIDS, malaria, and other diseases.

The emergence of resistance to anti-malarial drugs is an important problem that hinders malaria control. Resistance to chloroquine and sulfadoxine-pyrimethamine has spread in many endemic countries. ${ }^{3}$ Resistance to artemisinin, the drug recommended as first-line treatment for uncomplicated $P$. falciparum malaria, has been detected in five Southeast Asian countries. ${ }^{4}$ Poor patient adherence contributes to the emergence of drug-resistant malaria strains. ${ }^{5}$ Other consequences of poor adherence to treatment are lower cure rates, treatment failure, exacerbation of severe anemia, and increase in malaria prevalence. ${ }^{5}$

Compliance with prescribed treatment for a certain disease depends on the interaction between the patient, the drug, and the environment. The Health Belief Model, first conceptualized by Godfrey Hochbaum and later modified by Irwin Rosenstock, is the oldest and most widely used paradigm to explain and predict health behaviors. ${ }^{6}$ It hypothesizes that behavior is a function of an individual's psychological state of readiness, situational factors like the appearance of symptoms, and environmental conditions. According to the model, the likelihood of an individual taking action are influenced by perceived susceptibility to a 
certain disease or condition, perceived severity of the disease, perceived benefits of the recommended action and perceived barriers to action. Cues to action may be external (e.g., education from healthcare providers, media information, advice from family and/or friends) or internal (symptoms, perceptions). The probability of an advocated action occurring is highest when the perceived threat to the disease is high and the benefits outweigh the barriers. ${ }^{6}$ In previous studies, factors that influence compliance to antimalaria treatment included educational interventions, $, 8,9$ medication prepackaging, ${ }^{10}$ age ${ }^{11}$ sex $^{12}$ and distance to health facility. ${ }^{7}, 10,13$

To the best of the authors' knowledge, no study on compliance to anti-malarial treatment of malaria patients has been published to date. By studying the factors that influence non-compliance with malaria treatment, we endeavor to provide insights into these factors, help formulate interventions to improve compliance, and counteract the emergence of drug resistance.

Palawan was chosen as the study site because it is a Category A province. Its capital, Puerto Princesa is one of the areas in the province with the highest number of malaria cases.

The objective of this cross-sectional analytical study was to determine the association of selected factors with noncompliance to anti-malaria treatment among malaria patients in Puerto Princesa, Palawan, specifically: perceived susceptibility to malaria, perceived seriousness and severity of malaria, perceived benefits of medication, perceived barriers to treatment compliance, and cues to action.

\section{Materials and Methods}

The study population consisted of malaria patients with positive blood smears who sought treatment from health stations in certain barangays in Puerto Princesa from January to October 2010. The authors purposively selected accessible barangay health stations with the highest number of cases of malaria. With permission from the city health officer and the Roll Back Malaria office in Puerto Princesa, the investigators obtained a list of malaria patients. The study respondents were eligible participant-volunteers invited by barangay microscopists. We included permanent residents of Puerto Princesa who were able to communicate in English or Tagalog. We interviewed the parents or guardians of participants younger than 15 years old.

\section{Questionnaire}

We used an interviewer-administered structured questionnaire schedule consisting of 84 questions divided into 6 sections, namely, socioeconomic and demographic profile, cues to action, perceived barriers to treatment compliance (forgetfulness, medication-related factors, medication side effects), perceived benefits of medication, perceived seriousness and severity of malaria, and perceived susceptibility to malaria. The questionnaire was prepared by the investigators and pre-tested on 10 respondents who were dengue patients consulting at the Philippine General Hospital Outpatient Department.

\section{Estimation of compliance}

Compliance to treatment was determined through a participant's verbal report as elicited using the interview schedule. Patients who completed at least $80 \%$ of the recommended treatment dosage within the required number of days and who took at least $60 \%$ of the medicines on time were classified as compliant. Participants who missed at least $20 \%$ of the entire treatment regimen, or did not take more than $40 \%$ of the medicines at the designated time, or took the correct dosage at the scheduled time but fell short of the required number of days of treatment based on Philippine treatment guidelines ${ }^{14}$ were classified as noncompliant.

\section{Scoring system}

A scoring system was used for the levels of perception for the different factors (Table 1). For positive statements, a

Table 1. Scoring System Used for the Level of Perception for the Factors that may affect Compliance with Anti-malaria Treatment

\begin{tabular}{|c|c|c|c|c|}
\hline \multirow[t]{2}{*}{ Factor } & \multirow{2}{*}{$\begin{array}{c}\text { Score for Negative Perception } \\
\text { Raw score }\end{array}$} & \multicolumn{3}{|c|}{ Score for Positive Perception } \\
\hline & & $\%$ & Raw score & $\%$ \\
\hline 1. Perceived susceptibility & $0-4$ & $0-59$ & $5-8$ & $60-100$ \\
\hline 2. Perceived severity & $0-8$ & $0-59$ & $9-15$ & $60-100$ \\
\hline 3. Perceived benefits & $0-4$ & $0-59$ & $5-7$ & $60-100$ \\
\hline 4. Perceived barriers & & & & \\
\hline a. Side effects of medication & $0-1$ & $0-59$ & $2-3$ & $60-100$ \\
\hline b. Medication factors & $0-2$ & $0-59$ & 3-4 & $60-100$ \\
\hline c. Lack of access & $0-8$ & $0-59$ & $9-14$ & $60-100$ \\
\hline d. Forgetfulness & \multicolumn{4}{|c|}{ Disagreement with the statement in the questionnaire indicates a high level of perception towards malaria } \\
\hline 5. Cues to action & & & & \\
\hline a. Internal & & & & \\
\hline $\begin{array}{l}\text { 1.) Symptom perception } \\
\text { b. External }\end{array}$ & $0-1$ & $0-59$ & $2-3$ & $60-100$ \\
\hline 2) Health care provider and health services & $0-7$ & $0-59$ & $8-12$ & $60-100$ \\
\hline 3) Advice from family and/or friends & $0-2$ & $0-59$ & 3-5 & $60-100$ \\
\hline 4) Media and advertising & $0-14$ & $0-59$ & $15-25$ & $60-100$ \\
\hline
\end{tabular}


"yes" answer was given a score of one point and a "no" answer was given a score of zero. For negative statements, a "no" answer was given a score of one point and a "yes" answer was given a score of zero.

\section{Data analysis}

Descriptive statistics was used to estimate the prevalence proportion of non-compliance as well as sociodemographic factors, perceived factors, and cues to action.

Logistic regression models were constructed using backward elimination for each variable, namely, perceived susceptibility to malaria, perceived seriousness and severity of malaria, perceived benefits of the prescribed treatment regimen, perceived barriers to treatment compliance, and cues to action. The odds ratios derived from these models were adjusted for the confounding effect of extraneous variables. Stata ${ }^{\mathrm{TM}}$ (StataCorp, College Station, Texas) was used for statistical analysis.

\section{Ethics statement}

Informed consent was obtained from all study participants. In cases where the participant was a minor, legal permission was obtained through a parent's verbal assent and the minor's signature on the informed consent form.

\section{Results}

A total of 320 individuals who were diagnosed with malaria between January and December 2010 based on a positive blood smear participated in the study. Of these, 198 (61.8\%) had P. falciparum malaria, 88 (27.5\%) had P. vivax malaria, 13 (4\%) had mixed infection, and the rest could not recall the infecting species. Most of the participants $(83.4 \%$, $95 \%$ CI $78.9 \%-87.3 \%$ ) complied with the anti-malarial treatment regimen (Figure 1). Approximately half of the non-compliers failed to take $20 \%$ of the required drug dosage (Table 2).

Table 2. Frequency distribution of non-compliers by category of non-compliance

\begin{tabular}{lcc}
\hline \multicolumn{1}{c}{ Category of Non-compliance } & $\begin{array}{c}\text { No. } \\
(\mathbf{n = 5 3 )}\end{array}$ & \% \\
\hline $\begin{array}{l}\text { Failed to take } 20 \% \text { of the required dosage } \\
\text { Failed to take }>40 \% \text { of medicines at the designated } \\
\text { time }\end{array}$ & 24 & 45.3 \\
$\begin{array}{l}\text { Took the correct dosage at the scheduled time, but } \\
\text { fell short of the required number of days of } \\
\text { treatment }\end{array}$ & 12 & 22.6 \\
\hline
\end{tabular}

Table 3 shows the characteristics of compliers and noncompliers. The mean age of non-compliers (24.6 years) is not significantly different from the mean age of compliers $(22.9$ years) ( $\mathrm{p}=0.53)$. Most of the non-compliers completed at least

Table 3. Demographic Characteristics of Anti-malarial Treatment Regimen Received by Compliers and Non-compliers

\begin{tabular}{|c|c|c|c|c|c|}
\hline Characteristic & $\begin{array}{c}\text { Complier } \\
(\mathrm{n}=267)\end{array}$ & $\%$ of compliers & $\begin{array}{c}\text { Non-complier } \\
(n=53)\end{array}$ & $\begin{array}{c}\% \text { of } \\
\text { non-compliers }\end{array}$ & $\begin{array}{c}\text { Total } \\
(\mathrm{N}=320)\end{array}$ \\
\hline \multicolumn{6}{|l|}{ Infecting species } \\
\hline P. falciparum & 164 & 61.4 & 34 & 64.1 & 198 \\
\hline P. vivax & 74 & 27.7 & 14 & 26.4 & 88 \\
\hline Mixed & 11 & 4.1 & 2 & 3.8 & 13 \\
\hline Unknown & 18 & 6.7 & 3 & 5.7 & 21 \\
\hline \multicolumn{6}{|l|}{ Age (years) } \\
\hline$<15$ & 121 & 45.3 & 22 & 41.5 & 143 \\
\hline $15-24$ & 50 & 18.7 & 7 & 13.2 & 57 \\
\hline $25-64$ & 92 & 34.4 & 22 & 41.5 & 114 \\
\hline$\geq 65$ & 4 & 1.5 & 2 & 3.8 & 6 \\
\hline \multicolumn{6}{|l|}{ Sex } \\
\hline Male & 152 & 56.9 & 31 & 58.5 & 183 \\
\hline Female & 115 & 43.1 & 22 & 41.5 & 127 \\
\hline \multicolumn{6}{|l|}{ Educational attainment } \\
\hline None & 32 & 12.0 & 10 & 18.9 & 42 \\
\hline Primary & 130 & 48.7 & 25 & 47.2 & 155 \\
\hline Secondary & 75 & 28.1 & 10 & 18.9 & 85 \\
\hline Tertiary & 16 & 6.0 & 5 & 9.4 & 21 \\
\hline Others & 14 & 5.2 & 3 & 5.7 & 17 \\
\hline \multicolumn{6}{|l|}{ Treatment regimen } \\
\hline Chloroquine-sulfadoxine plus primaquine & 96 & 36.0 & 21 & 39.6 & 117 \\
\hline Chloroquine plus primaquine & 120 & 44.9 & 24 & 45.3 & 144 \\
\hline Artemether plus primaquine & 17 & 6.4 & 2 & 3.8 & 19 \\
\hline Chloroquine-sulfadoxine, artemether plus primaquine & 6 & 2.3 & 0 & 0 & 6 \\
\hline Unrecalled & 7 & 2.6 & 3 & 3 & 10 \\
\hline Others & 21 & 7.9 & 3 & 3 & 24 \\
\hline
\end{tabular}


a primary level of education. The most commonly used treatment regimens were chloroquine-sulfadoxine plus primaquine and chloroquine plus primaquine. About $40 \%$ of the participants who received these regimens were noncompliant with the treatment.

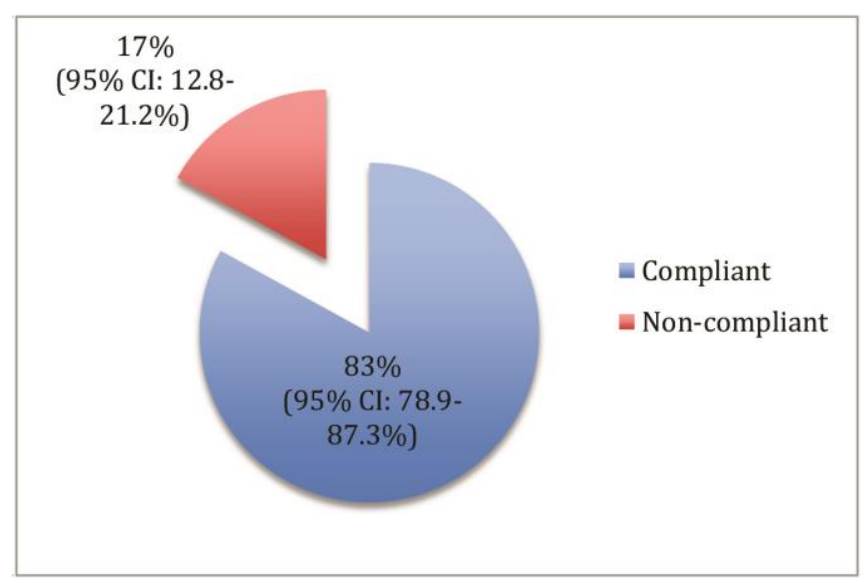

Figure 1. Distribution of Participants according to Compliance to Treatment

Figure 2 shows that experiencing adverse drug effects was the most common reason given by non-compliers for discontinuing their medications. This was followed by alleviation or improvement of their condition, and being busy.

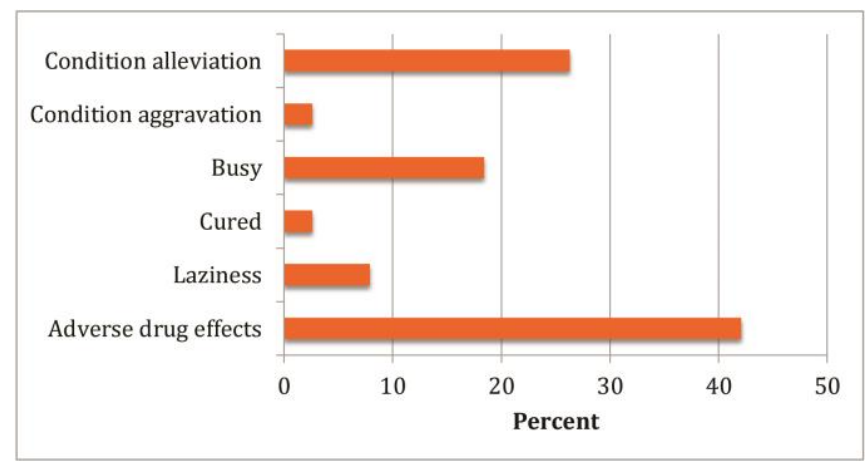

Figure 2. Distribution of Non-compliers according to the Reasons for Discontinuing Medications

\section{Cues to Action}

The proportion of non-compliers was higher for those with negative perception of cues to action, except for advice from family and friends for which there were more noncompliers among those with a positive perception of this cue to action (Figure 3). Analysis of the association between cues to action and compliance to treatment shows that the odds of a respondent not complying with the anti-malarial treatment regimen is three times greater among those who believed that feeling better means that cure of malaria has been achieved (Table 4).

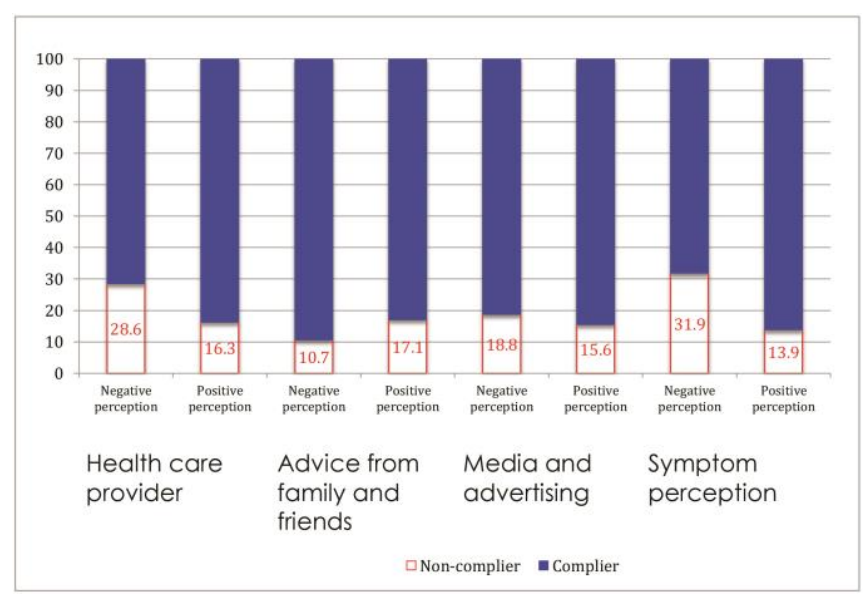

Figure 3. Level of Perception of Cues to Action

Table 4. Association of cues to action with non-compliance to treatment

\begin{tabular}{llll}
\hline Cues to Action & OR & p-value & $\mathbf{9 5 \% ~ C I ~}$ \\
\hline $\begin{array}{l}\text { Education from healthcare providers } \\
\text { and health services }\end{array}$ & 2.00 & 0.494 & $0.28-14.47$ \\
Advice from family and/or friends & 0.33 & 0.194 & $0.06-1.76$ \\
Media and advertising & 0.65 & 0.327 & $0.27-1.54$ \\
Symptom perception & $\mathbf{3 . 4 7}$ & $\mathbf{0 . 0 0 8}$ & $\mathbf{1 . 3 9 - 8 . 6 9}$ \\
\hline
\end{tabular}

\section{Perceived barriers to treatment}

For perceived barriers to treatment (forgetfulness, medication factors, adverse effects or side effects and lack of physical or financial access to treatment), a greater proportion of non-compliers was found, except for adverse effects or side effects (Figure 4). Perception of barriers to treatment refers to the perception of the level of challenge that social, personal, environmental, and economic obstacles pose to the performance of a specified behavior. Results show that a respondent who forgot to take at least one dose of the required treatment is 16 times more likely to be noncompliant than someone who did not forget a single dose (Table 5).

Table 5. Association of Perceived Barriers to Treatment with Non-compliance to Treatment

\begin{tabular}{llll}
\hline \multicolumn{1}{c}{$\begin{array}{c}\text { Perceived Barriers to } \\
\text { Treatment Compliance }\end{array}$} & OR & p-value & 95\% CI \\
\hline Forgetfulness & 16.61 & 0.000 & $7.37-37.46$ \\
Medication factors & 1.78 & 0.204 & $0.73-4.34$ \\
Adverse effects/Side effects & 0.52 & 0.092 & $0.24-1.11$ \\
Lack of access & 1.34 & 0.515 & $0.55-3.25$ \\
\hline
\end{tabular}




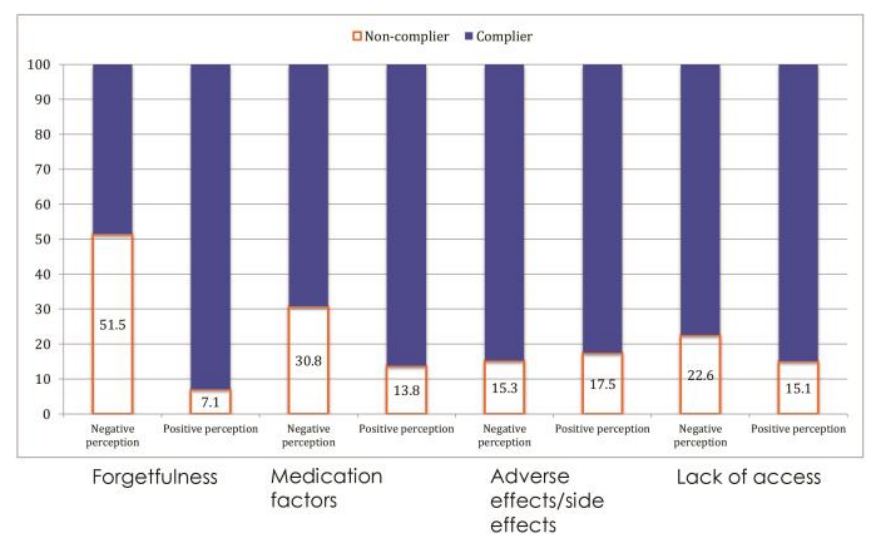

Figure 4. Level of Perception of Perceived Barriers to Treatment

\section{Perceived benefits of medication, perceived seriousness} and severity of malaria

For levels of perception of the perceived benefits of medication, the proportion of non-compliers was larger in those with negative perception (Figure 5). Similarly, a larger proportion of non-compliers was found among those with a negative perception of both perceived seriousness and severity of malaria and perceived susceptibility to malaria.

No significant association was found between noncompliance to treatment and the following factors: perceived benefits of medication, perceived seriousness and severity of malaria and perceived susceptibility to malaria. Interestingly, data showed that all non-compliers knew that severe malaria could lead to death, while one-third of the non-compliers believed that malaria is self-limiting (Table 6).

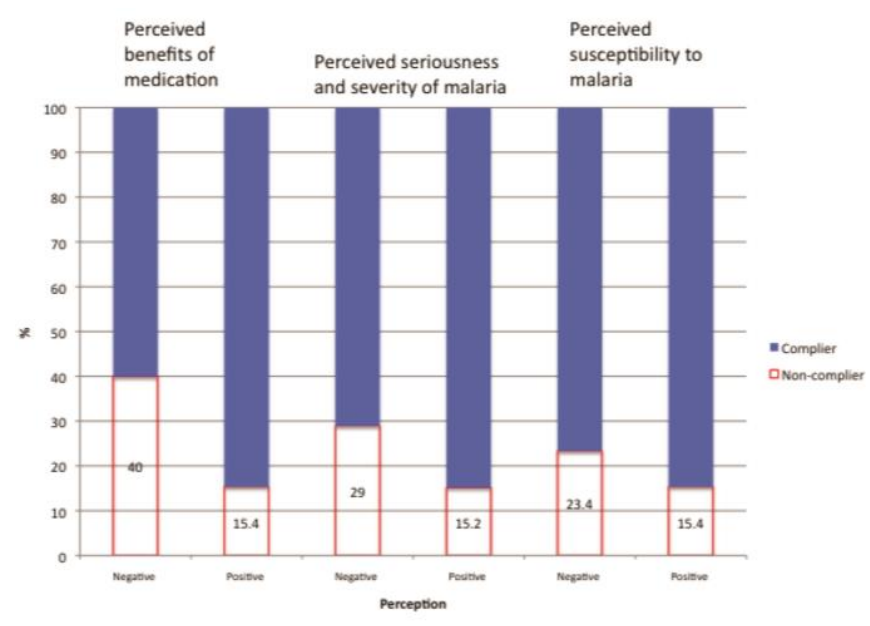

Figure 5. Level of Perception of Perceived Benefits of Medication, Perceived Seriousness and Severity of Malaria, and Perceived Susceptibility to Malaria
Table 6. Association of Perceived Benefits of Medication, Perceived Seriousness and Severity of Malaria, and Perceived Susceptibility to Malaria with Non-compliance to Treatment

\begin{tabular}{llll}
\hline \multicolumn{1}{c}{ Factor } & OR & p-value & 95\% CI \\
\hline Perceived benefits of medication & 2.33 & 0.257 & $0.54-10.00$ \\
$\begin{array}{l}\text { Perceived seriousness and severity of } \\
\text { malaria }\end{array}$ & 1.32 & 0.637 & $0.42-4.12$ \\
\begin{tabular}{l} 
Perceived susceptibility to malaria \\
\hline
\end{tabular} & 1.07 & 0.892 & $0.41-2.77$ \\
\hline
\end{tabular}

\section{Discussion}

The non-compliance rate with malaria treatment of study participants was $17 \%$. This is higher compared to other studies conducted in Uganda, where the noncompliance rate among malaria patients was $10 \%, 15$ and in Bangladesh, where the non-compliance rate was only $7 \% .{ }^{16}$ It is close to the non-compliance rate of $14.8 \%$ established among malaria patients in Malawi. ${ }^{17}$

The most common causative agent of malaria among study participants was $P$. falciparum, with chloroquinesulfadoxine plus primaquine as the most commonly prescribed treatment regimen. This shows that the treatment of P. falciparum malaria in the study area fails to adhere to the Philippine treatment guidelines for malaria, ${ }^{14}$ which recommends the use of artemether-lumefantrine as first-line treatment for uncomplicated $P$. falciparum malaria.

Cues to action, specifically symptom perception and perceived barriers to treatment were significantly associated with non-compliance with anti-malarial treatment. Individuals who believed that improvement or resolution of symptoms means that one has been cured of malaria and is therefore a valid reason for stopping medicine intake were three times more likely to be non-compliant with the treatment regimen. When patients with malaria start to feel better, they tend to stop taking their medicines or not to finish the prescribed number of days of treatment. ${ }^{18}$ Similarly, patients who feel that their condition is aggravated by the side effects of medicines are also inclined to stop treatment. ${ }^{19}$ Defervescence results rapidly from treatment with anti-malarials, an event that patients and caregivers often equate with cure. ${ }^{18}$ The antipyretic effect of anti-malarials has been one of the reasons for its indiscriminate use. As a result, WHO guidelines recommend that anti-malarials not be given to febrile patients until the presence of malaria parasites has been confirmed by laboratory or rapid diagnostic testing. ${ }^{20}$

The proportion of non-compliers was higher among those with a negative perception of cues to action, with the surprising exception of advice from family and friends. There were more non-compliers among those with a positive perception of advice from family and friends. It must be borne in mind, however, that advice from family and friends may either be encouraging or discouraging of the desired behavior, which is compliance to treatment. 
In contrast to the findings of other studies, ${ }^{10,12,13,21,22}$ healthcare provider and health services, advice of family or friends, and mass media had no significant association with non-compliance to treatment among the participants in this study. It is possible that the conduct of massive information campaigns about malaria in Palawan has already reached saturation point, and awareness of malaria is high among members of the general population. Therefore, other factors may be playing a more important role in influencing compliance to treatment of individuals with malaria

After correcting for the effect of confounders, only forgetfulness among the perceived barriers to treatment was found to have a significant association with non-compliance with treatment. A participant who forgot to take at least one dose of the required treatment was 16 times more likely to be non-compliant with treatment compared to someone who did not miss a single dose of medication. A previous study in Ghana has showed that forgetfulness regarding drug intake was reflective of initial intent to complete treatment. ${ }^{22}$ Forgetfulness was also established as a significant predictor of non-compliance with malaria treatment in Sri Lanka ${ }^{10}$ and Ecuador. $^{23}$

Improvement of patient counseling on the importance of observing the proper schedule for taking medication has been found to help improve compliance to treatment. ${ }^{12}$ In one randomized trial conducted in Ghana, patients who received supervised anti-malaria treatment by trained community health workers had a compliance rate similar to patients who self-administered the treatment, leading to the conclusion that a careful education program given during routine clinic visits may result in good compliance. ${ }^{24}$

Some misconceptions identified through participants' interview responses about susceptibility to malaria included the belief that drinking water with mosquito eggs or larvae or not eating on time causes the disease and that direct contact with a person with malaria leads to transmission of the infection. Even though perceived susceptibility to malaria was not significantly associated with noncompliance with treatment, these misconceptions are likely to hinder malaria prevention and control efforts.

\section{Limitations}

Because the minimum sample size of 336 participants was not reached, the study had a decreased power to detect significant associations. Selection bias, i.e., the investigators were unable to include eligible participants who were away at work during the conduct of the interviews, may also have affected the study's findings. Some interviews were conducted in the presence of barangay microscopists, which may have given rise to the Hawthorne effect. Recall bias may also have played a role as some participants were interviewed several months after their illness.

\section{Conclusion}

The factors that have been found to be significantly associated with non-compliance to anti-malarial treatment were symptom perception as a cue to action and forgetfulness as a perceived barrier to treatment compliance. Individuals who perceived that an improvement in symptoms implied cure of malaria were three times more likely to be non-compliant with treatment. An individual who forgot to take at least one dose of medication was 17 times more likely to be non-compliant with treatment compared to someone who did not forget to take a single dose. Given these, several measures may be formulated to improve the compliance rate to anti-malarial treatment, currently at $83 \%$ among malaria patients in Puerto Princesa. More effective ways of ensuring compliance with treatment may be explored, e.g., doing directly observed treatment and utilizing treatment partners that may help address the problem of forgetfulness. A more effective way of monitoring treatment adherence may also be devised. The fact that symptom improvement is not equivalent to cure must be stressed when advising patients. Emphasizing compliance to treatment and the consequences of noncompliance when conducting patient education activities may also help boost treatment compliance. Adherence to local malaria treatment guidelines can also be improved. Finally, research on other factors that may affect compliance with treatment but were not addressed by this study may aid in further increasing the treatment compliance rate.

\section{Acknowledgments}

We thank the following individuals who provided invaluable help in the conduct of this study: Puerto Princesa City Health Office staff, Puerto Princesa Municipal Government staff, Ms. Jane Rojo and the Rollback Malaria Office staff, Ms. Elena Villacorte, and Mr. Jonnel Poblete.

\section{References}

1. World Health Organization. Malaria Fact Sheet [Online] updated March 2014. [cited 2014 May]. Available from http://www.who.int/mediacentre/factsheets/fs094/en/.

2. World Health Organization. Philippines Country Profile in World Malaria Report [Online]. 2013 [cited 2014 May]. Available from http://www.who.int/malaria/publications/countryprofiles/profile_phl_en.pdf?ua $=1$

3. AntiMal. Development of New Drugs for the Treatment of Malaria [Online]. [cited 2010 October]. Available from http://www.antimal.eu/.

4. World Health Organization. Q\&A on artemisinin resistance [Online]. [cited 2014 May]. Available from http://www.who.int/malaria/media/artemisinin_resistance_qa/en/.

5. National Epidemiology Center. Field Health Services Information System Annual Report 2008 [Online]. [cited 2010 October]. Available from http://www.doh.gov.ph/ned/images/fhsis2008/2008_fhsis pdf.

6. Department of Health Promotion and Education College of Public Health University of the Philippines-Manila 2011 Reading notes in PHPE 210 Public Health Education. 
7. Ajayi IO, Browne EN, Bateganya F, et al. Effectiveness of artemisininbased combination therapy used in the context of home management of malaria: a report from three study sites in sub Saharan Africa. Malar J. 2008; 7:190

8. Okonkwo PO, Akpala CO, Okafor HU, Mbah AU, Nwaiwu O. Compliance to correct dose of chloroquine in uncomplicated malaria correlates with improvement in the condition of rural Nigerian children. Trans R Soc Trop Med Hyg. 2001; 95(3):320-4.

9. Yeboah-Antwi K, Gyapong JO, Asare IK, Barnish G, Evans DB, Adjei S. Impact of prepackaging antimalarial drugs on cost to patients and compliance with treatment. Bull World Health Organ. 2001; 79(5):394-9.

10. Reilley B, Aeyasinghe R, Pakianathar MV. Barriers to prompt and effective treatment of malaria in northern Sri Lanka. Trop Med Int Health. 2002; 7(9):744-9.

11. Souares A, Lalou R, Sene I, Sow D, Le Hesran JY. Factors related to compliance to anti-malarial drug combination: example of amodiaquine/sulphadoxine-pyrimethamine among children in rural Senegal. Malar J. 2009; 8:118.

12. Chanda P, Hawela M. Assessment of patient compliance to artemetherlumefantrine in Zambia. Malar J. 2005; 6:21.

13. Chuma J, Okungu V, Molyneux C. Barriers to prompt and effective malaria treatment among the poorest population in Kenya. Malar J. 2010; 9:144.

14. Department of Health-Philippines. Revised guidelines in the diagnosis and treatment of malaria 2009.

15. Fogg C, Bajunirwe F, Piola P, et al. Adherence to six-dose regimen of artemether-lumefantrine for treatment of uncomplicated Plasmodium falciparum malaria in Uganda. Am J Trop Med Hyg. 2004; 71(5):525-30.

16. Rahman MM, Dondorp AM, Day NP, et al. Adherence and efficacy of supervised versus non-supervised treatment with artemether/lumefantrine for the treatment of uncomplicated Plasmodium falciparum malaria in Bangladesh: a randomised controlled trial. Trans R Soc Trop Med Hyg. 2008; 102(9):861-7.
17. Bell DJ, Wootton D, Mukaka M, et al. Measurement of adherence, drug concentrations and the effectiveness of artemether-lumefantrine, chlorproguanil-dapsone or sulphadoxine-pyrimethamine in the treatment of uncomplicated malaria in Malawi. Malar J. 2009; 8:204.

18. World Health Organization. Assessment and monitoring of antimalarial drug efficacy for the treatment of uncomplicated falciparum malaria. Geneva, Switzerland: WHO; 2003

19. Kokwaro G. Ongoing challenges in the management of malaria. Malar J. 2009; 8 Suppl 1:S2

20. World Health Organization. Overview of malaria treatment [Online] [cited $2014 \quad$ May]. $\quad$ Available from http://www.who.int/malaria/areas/treatment/overview/en/.

21. Khantikul N, Butraporn P, Kim HS, Leemingsawat S, Tempongko MA, Suwonkerd W. Adherence to antimalarial drug therapy among vivax malaria patients in Northern Thailand. J Health Popul Nutr. 2009; 27(1):4-13.

22. Adjei GO, Darkwah AK, Goka BQ, et al. Parents' perceptions, attitudes and acceptability of treatment of childhood malaria with artemisinin combination therapies in Ghana. Ghana Med J. 2009; 43(3):99-106.

23. Yepez MC, Zambrano D, Carrasco F, Yepez RF. The factors associated with non-compliance with antimalarial treatment in Ecuadorian patients. Rev Cubana Med Trop. 2000; 52(2):81-9.

24. Asante KP, Owusu R, Dosoo D, et al. Adherence to artesunateamodiaquine therapy for uncomplicated malaria in rural Ghana: a randomized trial of supervised versus unsupervised drug administration. J Trop Med. 2009:529583.

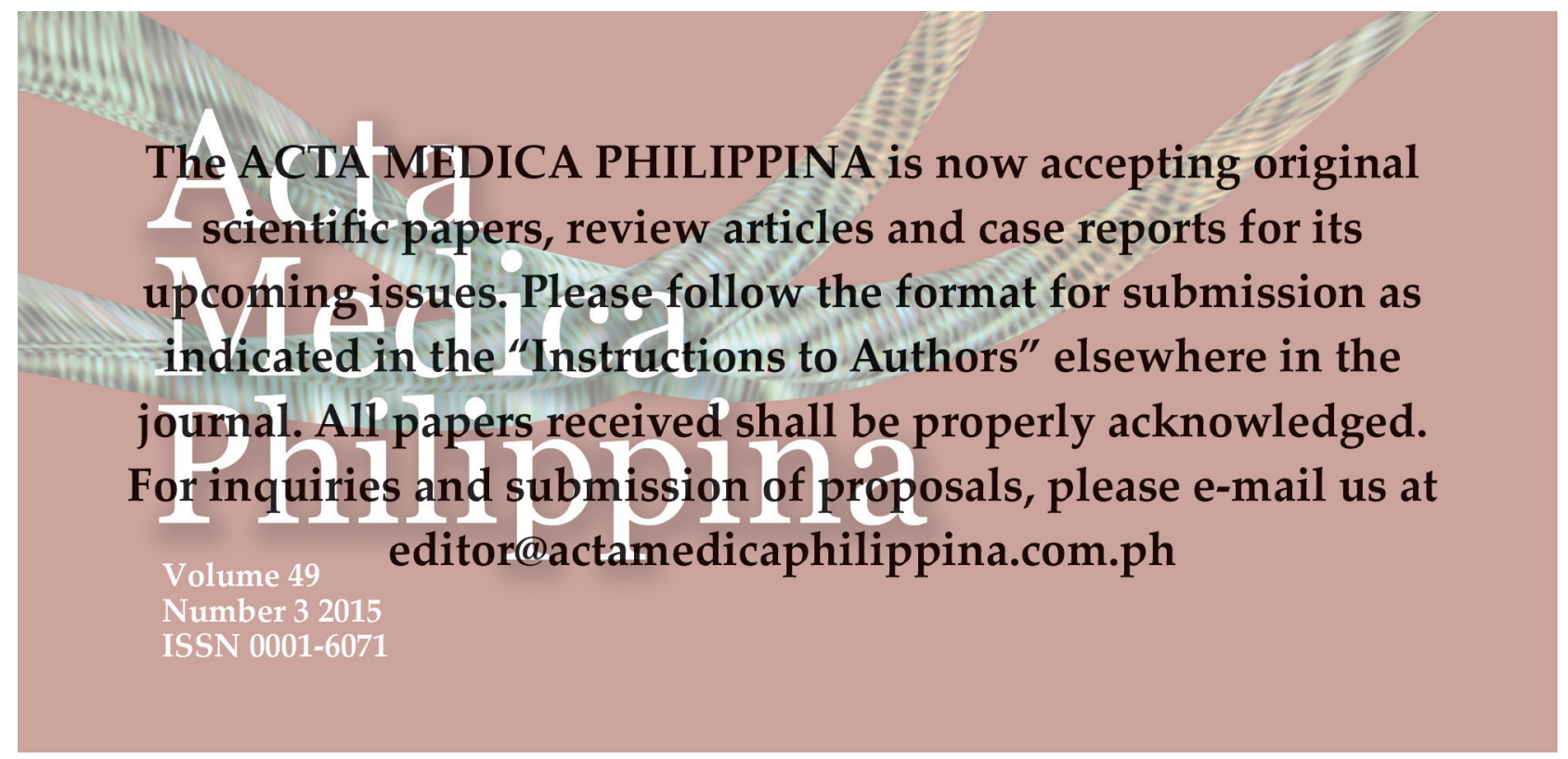

